\title{
Original Research: Treating Sleep Disorders Has Positive Outcomes in Psychiatric Illnesses
}

\author{
Vyas Umesh $1,2,3,4,5$, Mundey Kavita ${ }^{6}$ \\ ${ }^{1}$ Park Center Inc., Fort Wayne, USA \\ ${ }^{2}$ Indiana University School of Medicine, Fort Wayne, USA \\ ${ }^{3}$ Fort Wayne Medical Education Program-Family Medicine Residency, Fort Wayne, USA \\ ${ }^{4}$ University of Saint Francis, Fort Wayne, USA \\ ${ }^{5}$ Ivy Tech Community College of Indiana, Fort Wayne, USA \\ ${ }^{6}$ Veteran's Administration Medical Center (VAMC), Milwaukee, USA \\ Email: uvyaslife@yahoo.ca
}

Received 11 July 2015; accepted 16 November 2015; published 19 November 2015

Copyright (C) 2015 by authors and Scientific Research Publishing Inc.

This work is licensed under the Creative Commons Attribution International License (CC BY). http://creativecommons.org/licenses/by/4.0/

cc) (7) Open Access

\begin{abstract}
Introduction: Sleep and psychiatric disorders are common, and often co-morbid. Sleep disorders may predispose to development or exacerbation of psychiatric disorders. Authors hypothesized that treatment of sleep disorders improve outcomes in psychiatric illnesses. Methods: Charts of patients diagnosed with sleep disorders from October 2007 to December 2007 were reviewed. Outcomes in patients with co-morbid psychiatric disorders were recorded at 6, 12 and 24 months after initiation of sleep disorder treatment. These patients received a baseline psychiatric status score of 0 . Change in status at each subsequent time point was scored as: -2 (marked worsening), -1 (mild worsening), 0 (no change), +1 (mild improvement) or +2 (marked improvement). We individually compared change in average score at each time point to baseline using the signed rank test. We compared provider documented compliance to sleep therapies between patients with and without psychiatric disorders using Fisher's exact test. Results: Of 127 charts reviewed, 10 were excluded as patients died within follow-up period. No death was reported as suicide. 0 f 117 patients, 97.64\% were men, 2.36\% were women. Age range: 21 - 40: 7.69\%, 41 - 60: 42.74\%, 61 - 80: 47.87\%, >81: $1.70 \%$. 58 patients $(45.67 \%)$ had coexistent psychiatric diagnoses. There was no difference in provider documented compliance rate to sleep therapies between patients with and without psychiatric disorders at 6,12 and 24 months, (Fisher's p value $0.1031,0.2290$ and 0.2248 respectively). Psychiatric status progressively improved compared to baseline (Change in average score by $+0.45,+0.56$, and +0.79 at 6,12 , and 24 months, respectively, $p<0.0001$ ). Conclusion: Psychiatric disorders did not affect compliance to sleep related treatment. Treatment of co-morbid sleep disorders is associated with improvement in psychiatric disorders. Authors recommend need for prospective study with more subjects.
\end{abstract}




\section{Keywords}

\section{Psychiatric Illnesses/Disorders, Sleep Illnesses/Disorders}

\section{Introduction}

Sleep is an essential physiological need, and it is an active state that is critical for our physical, mental and emotional well-being. Sleep is also important for optimal cognitive functioning and sleep disruption results in functional impairment.

Sleep and psychiatric disorders are common disorders in clinical populations; existing data supports high rate of co-morbidity between them, and the disturbance in quality and quantity of sleep due to sleep disorders predisposes to the development or exacerbation of psychological distress and psychiatric illnesses. Likewise, the presence of psychiatric illnesses may complicate the diagnosis and treatment of sleep disorders.

Sleep disturbances are so commonly seen in psychiatric disorders that they are listed as diagnostic criteria under DSM (American Psychiatric Association) [1]. Sleep and psychiatric disorders, by themselves are disabling, the treatment of the co-morbidity may reduce needless disability. The data not only underscore the high frequency of psychopathology and psychological distress in sleep disorders and vice versa, but also suggest that combined treatment of both should become the standard of care for effective therapy [2].

\section{Literature Review}

$40 \%$ of those diagnosed with insomnia, in a population-based study, also have a psychiatric disorder, and with hypersomnia the prevalence of psychiatric disorder is 46.5\% [3]. Mood and anxiety disorders are associated with high rates of insomnia [4]. Prevalence for insomnia complaints was $12.7 \%$ in general population. The prevalence of sleep disorders mostly insomnia due to mental disorder was 5.6\%; primary psychiatric disorder diagnosed were applied to $8.4 \%$ [4].

Another study, which followed 1007 young adults at a health maintenance organization for 3.5 years, found that a history of insomnia at baseline not only predicated new onset depression, but also other psychiatric disorders (any anxiety disorder, alcohol abuse, drug abuse, and nicotine dependence), [5], the adjusted odds of developing a psychiatric disorders were highest for depression (OR = 3.95; 95\% CI, 2.2 - 7.0), was based on 16 percent of the sample who developed depression with history of insomnia at baseline, as compared with 4.6 percent who developed depression without a history of insomnia. The study's general findings are supported by another large study of 10,000 adults. That study found insomnia to have increased the risk of major depression by a similar magnitude (5-fold) and to have increased the risk of panic disorder even more strikingly, by 20 -fold $(\mathrm{OR}=20.3$; 95\% CI, 4.4 - 93.8) [6]. Insomnia is also a predictor of acute suicide among patients with mood disorders [7].

More than 2000 UK residents at baseline and 12-month follow up, measures of insomnia, depression and anxiety demonstrated that baseline insomnia was a significant risk factor for incidence of depression and anxiety at follow up (adjusted risk ratio of 2.71 and 2.28 respectively) [8].

Zurich longitudinal epidemiologic study revealed that a new onset of depression developed in $17 \%$ to $50 \%$ of patients with persistent, pure insomnia of $\geq 2$ weeks duration at a later interview, with predictive odds ratio of 1.6 to 1.9 [9].

Wisconsin Sleep Cohort, found substantially higher rates of psychiatric symptoms and disorders among those with daily Restless Leg Syndrome (RLS). Odds ratio to depression (Zung score > 50 or Anti-Depressant medication use) in those the daily RLS was 2.17 and 1.80 in those with "frequent" RLS (one or six times per week). For anxiety disorders, odds ratio were 3.41 and 2.42 for the two RLS groups respectively [10].

Psychiatric co-morbidity in Obstructive Sleep Apnea (OSA) patients was examined in a large prospective chart review of $>100,000$ Veterans Affairs Hospital OSA patients. A significantly high prevalence of psychiatric disorders was found in this group, as compared with a non-OSA population. High co-morbidity was found for major depression 21.8\%, anxiety disorder 16.7\%, PTSD 11.9\%, psychosis 5.1\%, and Bipolar disorder 3.3\% [11].

Depressive symptoms improve with treatment of OSA, and untreated OSA may contribute to treatment resis- 
tance in some cases of mood disorders [12]. OSA is a common sleep disorder, is well recognized as a cause of morbidity including psychiatric disorders. OSA needs to be excluded in cases of chronic or resistant depression and treatment of OSA will make it easier to treat depressive disorder [13]. Treatment of depression in OSA might improve acceptance of therapy, reduce sleepiness, fatigue and improve quality of life [14]. Reduction of depression scores (seven-item BDI) in OSA patients treated with continuous positive airway pressure (CPAP) [15]. Studies demonstrated high rates of depressive symptoms in OSA, as well as improvement of these symptoms with treatment of OSA [16]-[18].

Combined therapies for both depression and insomnia are superior to anti-depressant medications alone in patients with major depression [19] [20]. Study combining anti-depression medications with specific insomnia treatment (cognitive-behavioral therapy for insomnia) demonstrated that the combined treatment was superior to anti-depressant alone both in terms of depression out-come (61.5\% vs. $33.3 \%$ remission respectively) and insomnia out-come (50\% vs. $7.7 \%$ respectively) [21].

Guidelines on the management of insomnia from American Academy of Sleep Medicine (AASM) recommend that treatment of insomnia in patients with co-morbid psychiatric disorders follow the general guidelines of psychological and behavioral therapies, possibly coupled with a benzodiazepine receptor agonist, but they also note the potential usefulness of sedating anti-depressant or atypical anti-psychotic medications in certain populations [22].

Evidence suggests that individuals seeking medical attention for sleep complaints are more likely to have drug or alcohol abuse problems than the general population. Withdrawal from nicotine, alcohol and drug abuse is also associated with insomnia, and this may result in an increased risk of relapse if the sleep problems are remain unresolved [23].

The Post-Traumatic Stress Disorder (PTSD), 37\% had significant nightmare problems [24], and severity of sleep disturbance correlated with PTSD severity [25].

\section{Research Design}

Retrospective, observational, chart review study.

\section{Method}

Electronic medical record reviewed for diagnosis of sleep disorders at VAMC Milwaukee, WI, USA from October 2007 to December 2007, Figure 1. Patients with confirmed diagnosis and treatment for sleep disorders were included. Outcomes in patients with co-morbid psychiatric disorders were recorded at 6, 12 and 24 months after initiation of sleep disorder treatment.

Measurements of change in psychiatric disorder defined as follows:

Baseline score $=0$.

Marked improvement $=+2$.

Partial improvement $=+1$.

No change $=0$.

Partial worsening $=-1$.

Marked worsening $=-2$.

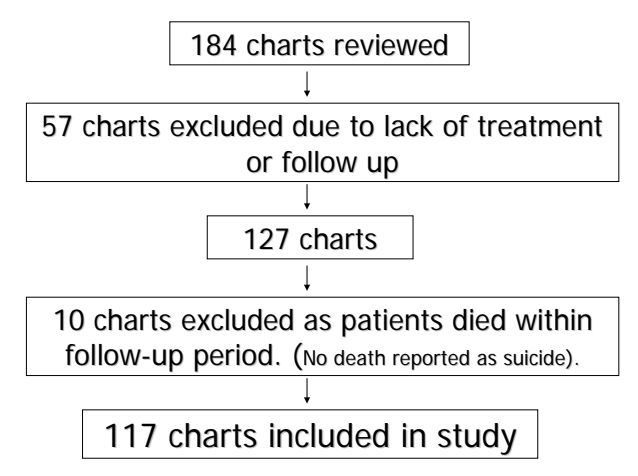

Figure 1. Details of chart reviewed. 
Various parameters used to assess outcomes of psychiatric disorders to assess improvement or worsening Table 1.

Change in average score for psychiatric disorders was compared individually at each time point to baseline using the signed rank test. Compliance was compared to sleep disorder treatment between patients with and without psychiatric disorders using Fisher's exact test. Difference in score changes at each time point to baseline was compared for a specific psychiatric disorder using Wilcoxon test.

Compliance to management defined as:

- Attendance of follow up visits in sleep clinic/primary care clinic/respiratory therapist clinic.

- Documentation of patient reported compliance to positive airway pressure therapy and other treatments offered.

- Clinic visit cancellation $\leq 2$ consecutive appointments.

\section{Discussion, Results and Conclusions}

Current data demonstrate important bidirectional relationship between sleep and psychiatric disorders, and mental disorders co-morbid with sleep disorders contribute to disease burden and adversely affect the outcome of patients with these conditions, therefore effective comprehensive evaluation and management of patients with sleep disorders require careful psychological assessment and evaluation for specific psychiatric disorders and vice versa. It also requires necessary independent pharmacological and psychological treatment of sleep disorder and psychiatric disorder.

Our study subject's demographic and age distribution (Age range: 21 - 40: 7.7\%, 41 - 60: 42.7\%, 61 - 80: 47.9\%, >81: 1.7\%) was very typical of Veteran's Administration Medical Center (VAMC), Figure 2. Our study supports treatment of co-morbid sleep disorders was associated with significant improvement in psychiatric disorders, Wilcoxon Signed rank test used, Figure 3 and Table 2. Psychiatric disorders did not affect compliance with sleep disorders treatment Table 3, Fisher's exact test used. Compliance among patients with psychiatric

Table 1. Parameters to assess outcomes of psychiatric disorders.

\begin{tabular}{|c|c|c|c|c|c|}
\hline & DSM Diagnosis & $\begin{array}{l}\text { Psychiatric } \\
\text { Medications }\end{array}$ & $\begin{array}{l}\text { MHC Follow } \\
\text { up/In-Pt } \\
\text { Management }\end{array}$ & $\begin{array}{c}\text { Documented } \\
\text { Improvement/Worsening }\end{array}$ & Substance Abuse \\
\hline $\begin{array}{c}\text { Marked } \\
\text { Improvement }(+2)\end{array}$ & Removal of Dx & Completely stopped & $\begin{array}{l}\text { Discharged from } \\
\text { MHC }\end{array}$ & $\begin{array}{c}\text { Significant } \\
\text { Improvement }\end{array}$ & $\begin{array}{c}\text { Stopped } \\
\text { completely }\end{array}$ \\
\hline $\begin{array}{c}\text { Partial } \\
\text { Improvement }(+1)\end{array}$ & $\begin{array}{l}\text { Mild/NOS } \\
\text { category of Dx }\end{array}$ & $\begin{array}{l}\text { Lower doses } \\
\text { required }\end{array}$ & $\begin{array}{l}\text { Less frequent } \\
\text { visit }\end{array}$ & $\begin{array}{l}\text { Mild/moderate } \\
\text { improvement }\end{array}$ & Reduced abuse \\
\hline \multicolumn{6}{|l|}{ No Change (0) } \\
\hline $\begin{array}{c}\text { Partial } \\
\text { Worsening }(-1)\end{array}$ & $\begin{array}{l}\text { New Mild } \\
\text { category Dx } \\
\text { added }\end{array}$ & $\begin{array}{c}\text { More } \\
\text { number/doses required }\end{array}$ & $\begin{array}{l}\text { More frequent } \\
\text { visits }\end{array}$ & $\begin{array}{l}\text { Mild/moderate } \\
\text { worsening }\end{array}$ & $\begin{array}{l}\text { More substance } \\
\text { abuse }\end{array}$ \\
\hline $\begin{array}{c}\text { Marked } \\
\text { Worsening }(-2)\end{array}$ & $\begin{array}{c}\text { Changed or } \\
\text { added severe } \\
\text { category of Dx }\end{array}$ & $\begin{array}{l}\text { Maximum doses and/or } \\
\text { augmentation required }\end{array}$ & $\begin{array}{c}\text { In-Pt } \\
\text { management } \\
\text { required }\end{array}$ & $\begin{array}{l}\text { Significant } \\
\text { worsening }\end{array}$ & $\begin{array}{c}\text { Relapse and/or } \\
\text { new substance } \\
\text { abuse }\end{array}$ \\
\hline
\end{tabular}

Table 2. Changes in psychiatric disease status after treatment.

\begin{tabular}{cccc}
\hline Comparison & Mean (Time 1) & Mean (Time 2) & 0.45 \\
\hline Baseline vs. 6 Months & 0 & 0.56 & 0.0004 \\
Baseline vs. 12 Months & 0 & 0.79 & $<002$ \\
Baseline vs. 24 Months & 0 & 0.56 & 0.1094 \\
6 Months vs. 12 Months & 0.45 & 0.79 & 0.0005 \\
6 Months vs. 24 Months & 0.45 & 0.79 & 0.0039
\end{tabular}


Table 3. Comparison of compliance among patients with and without psychiatric diagnosis.

\begin{tabular}{cc} 
Time & Fisher's $p$ Value \\
\hline 6 Months & 0.1031 \\
12 Months & 0.2290 \\
24 Months & 0.2248 \\
\hline
\end{tabular}

- 117 patients

- $97.6 \%$ were men, $2.4 \%$ were women

- 54 patients (46.2\%) had coexistent psychiatric diagnoses.

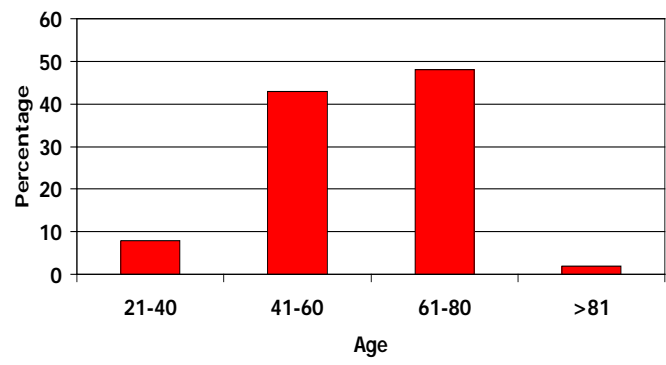

Figure 2. Demographics and age distribution.

\section{Change in psychiatric status during 2 year follow-up period}

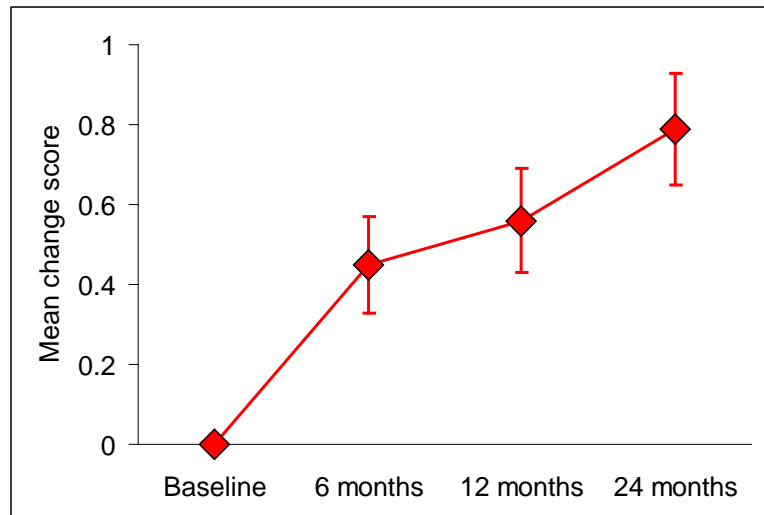

Figure 3. Change in psychiatric illness status during two years follow-up period.

diseases was 77\%, and compliance in patients without psychiatric diseases was $87 \%$. Wilcoxon test was used to find if there were significant differences in score change at each time point based on the presence of a specific psychiatric disorder. Authors found this was not statistically significant. This may be due to small number (N) for a specific psychiatric disorder; since most subjects had various co-existing psychiatric disorders Table 4. All statistical analysis was performed in SAS (Cary, NC).

\section{Limitations}

- Retrospective, chart review with small number of subjects.

- Single author reviewed all charts, therefore personal bias cannot be ruled out.

- Limitation of Likert Scale-Central tendency bias.

- Most sleep disorder patients had diagnosis of sleep-related breathing disorder (OSA).

- No objective compliance data were available for every subject to ascertain compliance.

- VA elderly male patient population; cannot be applied to general sleep clinic patient population.

There is a strong need for prospective studies with more subjects, to establish not only importance of management of sleep disorders in psychiatric disorders, but also need for comprehensive evaluation. 
Table 4. Wilcoxon test for significant difference in score change (baseline vs. 6, 12, 24 months) based on presence of psychiatric disorder.

\begin{tabular}{cccc}
\hline Psychiatric Disorder & $\begin{array}{c}\text { Mean Score Change } \\
\text { (disorder not present) }\end{array}$ & $\begin{array}{c}\text { Mean Score Change } \\
\text { (disorder present) }\end{array}$ & p value \\
\hline Psychotic & 0.46 & 0 & 0.4814 \\
6 months & 0.57 & 0 & 0.4061 \\
12 months & 0.81 & 0 & 0.2875 \\
24 months & & & 0.6171 \\
Mood & 0.60 & 0.42 & 0.3515 \\
6 months & 0.90 & 0.49 & 0.3701 \\
12 months & 1.10 & 0.72 & 0.7311 \\
24 months & & & 0.7237 \\
Anxiety & 0.43 & 0.63 & 0.3703 \\
6 months & 0.53 & 0.75 & 0.1009 \\
12 months & 0.73 & 1.13 & 0.1159 \\
24 months & & & 0.0701 \\
Sub-related & 0.61 & 0.12 & 0.1457 \\
months & 0.71 & 0.24 & 0.0396 \\
24 months & 0.97 & 0.41 & 0.0983 \\
PTSD & & & 0.67 \\
6 months & 0.32 & 0.90 & 1.10 \\
12 months & 0.35 & & \\
\hline
\end{tabular}

\section{Conflict of Interest}

The authors declare that they have no conflict of interest.

\section{Hypothesis}

Authors hypothesized that treatment of sleep disorders improve outcomes in psychiatric illnesses.

\section{Objectives}

Evaluate effect of treatment of sleep disorders on outcomes of psychiatric disorders.

\section{References}

[1] (2013) Diagnostic and Statistical Manual of Mental Disorders. 5th Edition, DSM-5.

[2] Michael, S.J. (2009) Update on Sleep and Psychiatric Disorders. Chest, 135, 1370-1379. http://dx.doi.org/10.1378/chest.08-1834

[3] Ford, D.E. and Kamerow, D.B. (1989) Epidemiologic Study of Sleep Disturbances and Psychiatric Disorders. An Opportunity for Prevention? Journal of the American Medical Association, 262, 1479-1484. http://dx.doi.org/10.1001/jama.1989.03430110069030

[4] Ohayon, M.M. (1997) Prevalence of DSM IV Diagnostic Criteria of Insomnia; Distinguishing Insomnia Related to Mental Disorders from Sleep Disorders. Journal of Psychiatric Research, 31, 333-346. http://dx.doi.org/10.1016/S0022-3956(97)00002-2

[5] Breslau, N., Roth, T., Rosenthal, L., et al. (1996) Sleep Disturbance and Psychiatric Disorders: A Longitudinal Epidemiological Study of Young Adults. Biological Psychiatry, 39, 411-418. http://dx.doi.org/10.1016/0006-3223(95)00188-3

[6] Weissman, M.M., Greenwald, S., Nino-Murcia, G., et al. (1997) The Morbidity of Insomnia Uncomplicated by Psychiatric Disorders. General Hospital Psychiatry, 19, 245-250. http://dx.doi.org/10.1016/S0163-8343(97)00056-X

[7] Fawcett, J., Scheftner, W.A., Fogg, L., et al. (1990) Time-Related Predictors of Suicide in Major Affective Disorder. American Journal of Psychiatry, 147, 1189-1194. http://dx.doi.org/10.1176/ajp.147.9.1189

[8] Morphy, H., Dunn, K.M., Lewis, M., et al. (2007) Epidemiology of Insomnia: A Longitudinal Study in a UK Population. Sleep, 30, 274-280. 
[9] Buysse, D.J., Angst, J., Gamma, A., et al. (2008) Prevalence, Course and Co-Morbidity of Insomnia and Depression in Young Adults. Sleep, 31, 473-480.

[10] Winkelman, J.W., Finn, L. and Young, T. (2006) Prevalence and Correlates of RLS Symptoms in Wisconsin Sleep Cohort. Sleep Medicine, 7, 545-552. http://dx.doi.org/10.1016/j.sleep.2006.01.004

[11] Sharafkhaneh, A., Giray, N., Richardson, P., et al. (2005) Association of Psychiatric Disorders and Sleep Apnea in Large Cohort. Sleep, 28, 1405-1411.

[12] Baran, A.S. and Richert, A.C. (2003) Obstructive Sleep Apnea and Depression. CNS Spectrums, 8, 128-134.

[13] Kaplan, R. (1992) Obstructive Sleep Apnea and Depression-Diagnostic and Treatment Implications. Australian and New Zealand Journal of Psychiatry, 26, 586-591. http://dx.doi.org/10.3109/00048679209072093

[14] Harris, M., Glozier, N., Ratnavadivel, R., et al. (2009) Obstructive Sleep Apnea and Depression. Sleep Medicine Reviews, 13, 437-444. http://dx.doi.org/10.1016/j.smrv.2009.04.001

[15] Schwartz, D.J. and Karatinos, G. (2007) For Individuals with OSA, Institution of CPAP Therapy Is Associated with an Amelioration of Symptoms of Depression Which Is Sustained Long Term. Journal of Clinical Sleep Medicine, 3, 631635.

[16] Mosko, S., Zetin, M., Glen, S., et al. (1989) Self-Reported Depressive Symptomatology, Mood Ratings and Treatment Outcome in Sleep Disorders Patients. Journal of Clinical Psychology, 45, 51-60. http://dx.doi.org/10.1002/1097-4679(198901)45:1<51::AID-JCLP2270450107>3.0.CO;2-H

[17] Ohayon, M.M. (2003) The Effects of Breathing-Related Sleep Disorders on Mood Disturbances in the General Population. Journal of Clinical Psychiatry, 64, 1195-1200. http://dx.doi.org/10.4088/JCP.v64n1009

[18] Millanan, R.P., Fogel, B.S., McNamara, M.E., et al. (1989) Depression as a Manifestation of Obstructive Sleep Apnea; Reversal with Nasal Continuous Positive Airway Pressure. Journal of Clinical Psychiatry, 50, 348-351.

[19] Fava, M., McCall, W.V., Krystal, A., et al. (2006) Eszopiclone Co-Administered with Fluoxetine in Patients with Insomnia Coexisting with Major Depressive Disorder. Biological Psychiatry, 59, 1052-1060. http://dx.doi.org/10.1016/j.biopsych.2006.01.016

[20] Krystal, A., Fava, M., Rubens, R., et al. (2007) Evaluation of Eszopiclone Discontinuation after Co-Therapy with Fluoxetine for Insomnia with Coexisting Depression. Journal of Clinical Sleep Medicine, 3, 48-55.

[21] Manber, R., Edinger, J.D., Gress, J.L., et al. (2008) Cognitive Behavioral Therapy for Insomnia Enhances Depression Outcome in Patients with Co-Morbid Major Depressive Disorder and Insomnia. Sleep, 31, 489-495.

[22] Schutte-Rodin, S., Broch, L., Buysse, D., et al. (2008) Clinical Guideline for the Evaluation and Management of Chronic Insomnia in Adults. Journal of Clinical Sleep Medicine, 4, 487-504.

[23] Roth, T. (2009) Does Effective Management of Sleep Disorders Reduce Substance Dependence? Drugs, 69, 65-75. Does Effective Management of Sleep Disorders Reduce Depressive Symptoms and the Risk of Depression? Drugs, 69, 43-64.

[24] Calhoun, P.S., Wiley, M., Dennis, M.F., et al. (2007) Objective Evidence of Sleep Disturbance in Women with Posttraumatic Stress Disorder. Journal of Traumatic Stress, 20, 1009-1018. http://dx.doi.org/10.1002/jts.20255

[25] Waldrop, A.E., Back, S.E., Sensenig, A., et al. (2008) Sleep Disturbance Associated with Posttraumatic Stress Disorder and Alcohol Dependence. Addictive Behaviors, 33, 328-335. http://dx.doi.org/10.1016/j.addbeh.2007.09.019 